\title{
Better Islet Function and Cardiovascular Autonomic Function in Chinese Type 2 Diabetic Patients with Pure Small Fiber Neuropathy than with Mixed Neuropathy
}

\author{
Chenxi Li $\cdot$ Weimin Wang $\cdot$ Wenyu Ni $\cdot$ Yu Jin $\cdot$ Simin Guo \\ Jiewen Jin $\cdot$ Chuhui Chen $\cdot$ Wei Chen $\cdot$ Yan Bi (1) · Dalong Zhu
}

Received: May 17, 2021 / Accepted: June 28, 2021 / Published online: August 2, 2021

(c) The Author(s) 2021

\section{ABSTRACT}

Introduction: The clinical characteristics and outcomes of small fiber neuropathy (SFN) in Chinese patients with type 2 diabetes mellitus (T2DM) have not been thoroughly described. In this study, we investigated the metabolic and

Chenxi Li, Weimin Wang and Wenyu Ni contributed equally to this work.

Supplementary Information The online version contains supplementary material available at https:// doi.org/10.1007/s13300-021-01111-0.

C. Li · W. Wang · W. Ni · Y. Jin · S. Guo .

W. Chen · Y. Bi $(\varangle) \cdot$ D. Zhu $(\bowtie)$

Department of Endocrinology, Drum Tower

Hospital Affiliated to Nanjing University Medical

School, No. 321 Zhongshan Road, Nanjing 210008,

Jiangsu, China

e-mail: biyan@nju.edu.cnD. Zhu

e-mail: zhudalong@nju.edu.cn

Y. Jin

Department of Osteoporosis, Lianyungang Clinical College of Nanjing Medical University,

Lianyungang, Jiangsu, China

J. Jin

Department of Endocrinology, The First Affiliated Hospital, Sun Yat-Sen University, Guangzhou, Guangdong, China

C. Chen

Department of Endocrinology, Fujian Provincial

Hospital, Fuzhou, Fujian, China neurological indexes and the prognosis of patients with T2DM based on skin biopsy.

Methods: A total of 34 healthy Chinese volunteers were recruited for skin biopsy to establish the reference range of intra-epidermal nerve fiber density (IENFD), and 89 patients with T2DM attending the Nanjing Drum Tower Hospital were evaluated at baseline. Of these 89 patients, 17 with pure SFN and nine with mixed diabetic polyneuropathy (DPN) were reassessed at the end of the follow-up.

Results: Glycated hemoglobin and postprandial blood glucose levels were lower $(P=0.005$ and $P=0.041$, respectively) and postprandial C-peptide and insulin levels were higher $(P=0.001$ and $P=0.019$, respectively) in the pure SFN group than in the mixed DPN group. A partial correlation study showed that there was a negative correlation between IENFD of the distal leg and cardiovascular autonomic reflex test (CART) scores $(r=-0.513, P=0.001)$ after adjusting for age and duration of diabetes. Only vitamin $B 12$ level $(P=0.028)$ and motor nerve conduction velocity (MCV) of the common peroneal nerve $(P=0.045)$ were increased in the patients with pure SFN at the final visit while MCVs of the common peroneal nerve $(P=0.025)$ and tibial nerve $(P=0.047)$ were decreased in the mixed DPN group at the final visit.

Conclusion: Better islet function and cardiovascular autonomic function were observed in patients with pure SFN compared with mixed 
DPN. The metabolic and neurological indexes remained relatively stable in the patients with pure SFN during the follow-up.

Keywords: Small fiber neuropathy; Diabetic polyneuropathy; Cardiovascular autonomic neuropathy; Type 2 diabetes mellitus; Skin biopsy

\section{Key Summary Points}

Why carry out this study?

Approximately 1.56 billion people suffer from diabetes in mainland China, and small fiber neuropathy (SFN) is a common complication of diabetes that increases the risk of foot ulcers and amputation.

Although skin biopsy is considered the gold standard for SFN, it has not been widely used in China due to its invasive nature.

The aim of this study was to investigate metabolic and neurological indexes and the prognosis of patients with type 2 diabetes mellitus (T2DM) based on skin biopsy in China.

\section{What was learned from the study?}

Better islet function and cardiovascular autonomic function were observed in Chinese T2DM patients with pure SFN compared with those with mixed diabetic polyneuropathy (DPN).

The metabolic and neurological indexes of patients with pure SFN remained relatively stable during the follow-up period.

\section{INTRODUCTION}

A recent epidemiological survey indicated that approximately 1.56 billion people suffer from diabetes in mainland China [1]. Of these, about $30 \%$ also have diabetic polyneuropathy (DPN), which increases the risk of foot ulcers and amputation [2]. Small fiber neuropathy (SFN) is a specific type of DPN that affects small-diameter $(<7 \mu \mathrm{m})$ sensory and/or autonomic axons, most commonly impairing unmyelinated C-fibers and thinly myelinated small A $\delta$-fibers [3]. The main effects associated with SFN are autonomic neuropathy and paraesthesia related to pain, numbness, coldness, and burning sensation, while the nerve conduction velocity (NCV) is usually normal.

Skin biopsy is an effective method to diagnose SFN with high specificity and sensitivity. However, although skin biopsy is considered the gold standard for diagnosing SFN, it has not been widely used by endocrinology departments in China due to the invasive nature of the procedure. Moreover, it has been found that SFN is also common in diabetic patients with large nerve fiber neuropathy manifesting as abnormal skin biopsy results and NCV.

In this study, diabetic patients reporting symptoms characteristic of SFN were enrolled and received skin biopsies with the aim to analyze the metabolic and neurological characteristics, including cardiovascular autonomic function, of the different groups. We also explored correlated factors that may have an impact on the intra-epidermal nerve fiber density (IENFD) and facilitate the early recognition of patients with diabetic neuropathy. Finally, we followed up patients with pure SFN and mixed DPN in an attempt to understand the difference in prognosis.

\section{METHODS}

\section{Subjects}

A total of 103 diabetic patients complaining of symptoms related to SFN, aged between 20 and 80 years, were enrolled from the Department of Endocrinology at Nanjing Drum Tower Hospital between December 2015 and April 2020. All recruited participants provided written informed consent before enrollment. The study (NCT04071535) was registered at ClinicalTrials.gov and was compliant with the declaration of Helsinki 1964 and its later amendments. 
Diabetes was diagnosed according to the World Health Organization criteria [4]. Ultimately, 89 patients with type 2 diabetes mellitus (T2DM) were included in this study (Fig. 1).

Pure SFN was defined as abnormal IENFD and normal NCV. Mixed DPN was defined as concomitant abnormal IENFD and NCV. Exclusion criteria included patients with type 1 diabetes, peripheral vascular disease, foot ulcer, history of stroke, thyroid disease, vitamin B12 deficiency, and other causes of peripheral neuropathy.

\section{Physical Examinations and Laboratory Measurements}

Fasting blood samples were collected in the morning after $12 \mathrm{~h}$ of fasting. HbA1c levels were performed by high-performance liquid chromatography and according to the National Glycohemoglobin Standardization Program (NGSP). The fasting blood glucose (FBG) was determined by the glucose oxidase method. Fasting insulin, folate, Vitamin B12, and 25-hydroxy $(\mathrm{OH})$ vitamin $\mathrm{D}$ were performed by chemiluminescence. Insulin sensitivity was evaluated by using the homeostasis model assessment of insulin resistance (HOMA-IR)

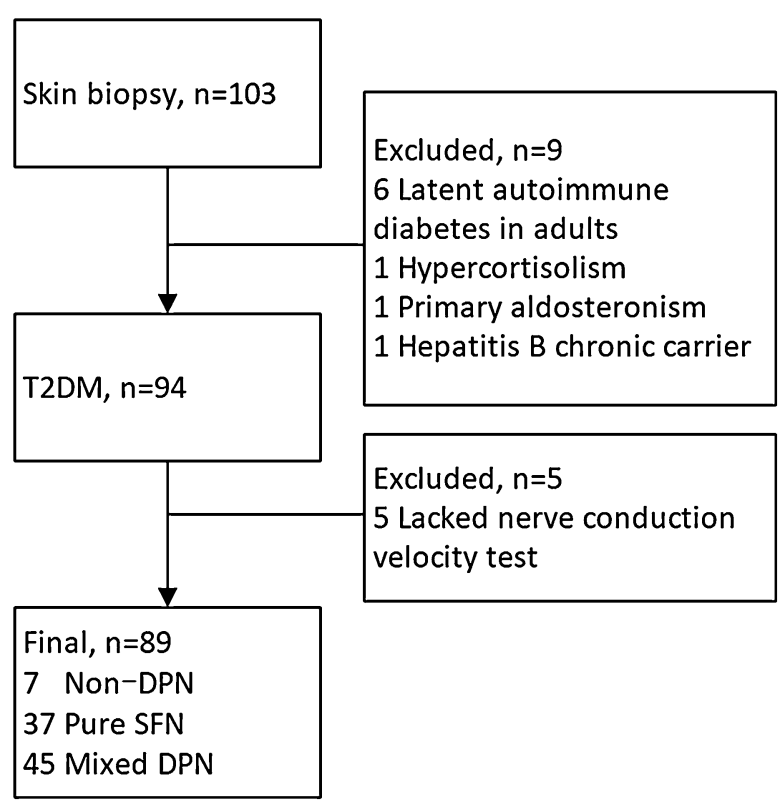

Fig. 1 Flowchart of participating patient enrollment formula: HOMA-IR = fasting blood glucose $(\mathrm{mmol} / \mathrm{L}) \times$ fasting insulin $((\mu \mathrm{IU} / \mathrm{mL}) / 22.5$. Total cholesterol (TC), total triglyceride (TG), and high-density lipoprotein cholesterol (HDLC) were measure by enzymatic colorimetric assay. Low-density lipoprotein cholesterol (LDL-C) was calculated by Friedewald's formula.

\section{Neuropathy Symptom Score and Numerical Pain Rating Scale}

All participants were asked to complete the Neuropathy Symptom Score (NSS) and the Numerical Pain Rating Scale (NPRS). The NSS consists of questions on symptoms in the lower limbs, such as burning, numbness, or tingling, when the symptoms usually happened, and ways used to alleviate the discomfort. The maximum score was 9 , and a symptom score of 3-4 was defined as mild symptoms; $5-6$ as moderate symptoms; and 7-9 as severe symptoms [5]. An 11-point NPRS was used to evaluate pain intensity in patients with DPN, where $0=$ no pain and $10=$ worst possible pain [6].

\section{NCV Test}

The NCV test was performed by a specialized technician at a room temperature of $26^{\circ} \mathrm{C}$. The $\mathrm{NCV}$ test results were considered to be abnormal if more than two nerve conduction velocities were less than the reference value. A patient with abnormal NCV and a symptom or sign of neuropathy was defined as having confirmed diabetic sensorimotor polyneuropathy [7].

\section{Cardiovascular Autonomic Reflex Tests}

Cardiovascular autonomic reflex tests (CARTs) are used to assess cardiovascular autonomic neuropathy (CAN), including blood pressure (BP) variability in response to standing up (postural BP change), heart rate variability (HRV) during deep breathing (HRV_deep breathing), HRV during the Valsalva maneuver (Valsalva ratio), and HRV during the lying-tostanding test (30:15 test). Each test is scored separately, with a score of $0=$ normal, a score of 0.5 = borderline, and a score of $1=$ abnormal. 
Patients with a total score $\geq 2$ were defined as patients with CAN.

\section{SUDOSCAN Test}

SUDOSCAN (Impeto Medical, Paris, France) is a non-invasive mobile device that is used to measure autonomic neuropathy affecting sudomotor function [8]. In this test, patients place palms and feet on detecting stainless steel electrodes, and a low direct voltage is applied. Quantitative results are measured as electrochemical skin conductance of the hands and feet (HESC and FESC, respectively) levels (in microseconds). The severity of sudomotor dysfunction was classified as follows: none (ESC > $60)$, moderate $(40 \leq \mathrm{ESC} \leq 60)$, or severe $(\mathrm{ESC}<40)$.

\section{Skin Biopsy and Frozen Section Preparation}

After local anesthesia with lidocaine, a skin biopsy was performed at the proximal thigh and distal thigh by using a 4-mm disposable punch. Skin punch biopsies were dehydrated in 30\% sucrose solution and embedded in an optimum cutting temperature (OCT) compound (SAKURA Tissue-Tek ${ }^{\circledR}$ O.C.T. Compound; Sakura Finetech, Torrance, CA, USA). Tissue blocks were frozen at $-20^{\circ} \mathrm{C}$ and cut into $50-\mu \mathrm{m}$ frozen slices on a cryostat; each microslide contained three discontinuous slices.

\section{Immunofluorescence and Epidermal Nerve Counting}

Microslides were rinsed three times (10 $\mathrm{min}$ each rinse) in phosphate buffered saline (PBS). Slices were permeabilized for $4 \mathrm{~h}$ with $0.3 \%$ Triton-X100, then incubated with a rabbit monoclonal antibody to PGP9.5 (1:1000; Abcam, Oxford, UK; ab108986) overnight at $4{ }^{\circ} \mathrm{C}$. The slices were then rinsed in PBST (PBS containing $0.1 \%$ Tween 20 ), followed by Cy3conjugated goat anti-rabbit antibody (1:2000; Servicebio Technology Co., Ltd., Wuhan, China) for $2 \mathrm{~h}$ at room temperature (RT). Nuclei were stained with a DAPI solution for $10 \mathrm{~min}$ at
RT in the dark ( $50 \mu$ l for each sample; Servicebio Technology Co., Ltd.).

Images were acquired using laser scanning confocal microscopy (TCS-SP8; Leica Microsystems, Wetzlar, Germany) and overlaid by LAS X software (Leica Microsystems). Each slice was scanned through the Z-axis every $5 \mu \mathrm{m}$. The quantification of IENFD was performed according to European Federation of Neurological Societies (EFNS) guidelines, and nerves crossing the basement membrane of the epidermis were regarded as effective counts [9]. Two welltrained technicians separately measured IENFD and reached an agreement if the data were different.

\section{Statistical Analysis}

Data are presented as the mean \pm standard deviation (SD) or mean (range). The analysis was performed using SPSS software 22.0 (SPSS IBM Corp., Armonk, NY, USA). For continuous variables, Student's $t$ test and one-way analysis of variance were used for normally distributed variables, while the Wilcoxon rank-sum test and Kruskal-Wails $H$ test were used for nonnormally distributed variables. The Chi-square test or Fisher's exact test was used for dichotomous variables. Image J software version 1.50 (National Institutes of Health, Bethesda, MD, USA) was used to count the length of the epidermis. $P$ values $\leq 0.05$ were considered to be statistically significant.

\section{RESULTS}

\section{Establishment of IENFD Reference Range}

Healthy Chinese volunteers $(n=34 ; 18$ men, 16 women) were recruited for this study to establish an IENFD reference range. The mean $( \pm$ SD) age of this cohort of healthy subjects was $51.7 \pm 14.5$ years, and the mean glycated hemoglobin (HbA1c) was $5.4 \pm 0.4 \%$. The mean IENFD at the proximal thigh was $20.7 \pm 6.0 / \mathrm{mm}$ (lower 5 th percentile $10.0 / \mathrm{mm}$ ), and the mean IENFD at the distal thigh was $11.3 \pm 3.5 / \mathrm{mm}$ (lower 5 th percentile $8.1 / \mathrm{mm}$ ). 


\section{Comparison of Normal IENFD Between Different Sexes and Ages}

There were no differences in the distal thigh and proximal thigh IENFD values between males and females. To determine if age had an effect, the subjects were separated into two groups based on their age: 20-50 years and 51-80 years. No significant differences were found between the two age groups (Electronic Supplementary Material [ESM] Tables 1,2).

\section{Clinical Characteristics of Subjects Participating in the Skin Biopsy}

Representative PGP9.5 immunofluorescence in the human skin biopsy is shown in Fig. 2. IENFD was significantly lower in a diabetic patient with SFN (Fig. 2b) than in a healthy subject (Fig. 2a).

Patients were classified into non-DPN, pure SFN, and mixed DPN groups according to the established IENFD reference range and NCV test results (Table 1). There were no differences in age, sex, body mass index (BMI), or the duration of diabetes among the three groups. The percentages of each group with a family history of diabetes, smoking, and alcohol intake were also similar. BP and resting heart rate were higher in the mixed DPN group than in the non-DPN group (all $P \leq 0.05$ ).

Additionally, the levels of HbA1c and postprandial blood glucose were lower $(P=0.005$ and $P=0.041$, respectively) and those of postprandial C-peptide and insulin were higher ( $P=0.001$ and $P=0.019$ for each) in the pure SFN group than in the mixed DPN group. Regarding microvascular complications, the albumin-to-creatinine ratio (ACR) was higher in the mixed DPN group than in the non-DPN group $(P=0.016)$. The level of 25 -hydroxyvitamin D was lower in the mixed SFN group than in the non-DPN group $(P=0.014)$. No differences were seen in the lipid profiles, estimated glomerular filtration rate (eGFR) or folate or vitamin B12 levels among the three groups.

Subjects with T2DM underwent neuropathy examinations, including IENFD, NSS, NPRS, CART scores, and SUDOSCAN and NCV tests (Table 2). The IENFD of the proximal and distal leg was significantly lower in the pure SFN group and the mixed DPN group than in the non-DPN group $(P=0.004$ and $P=0.000$, respectively), but there was no significant
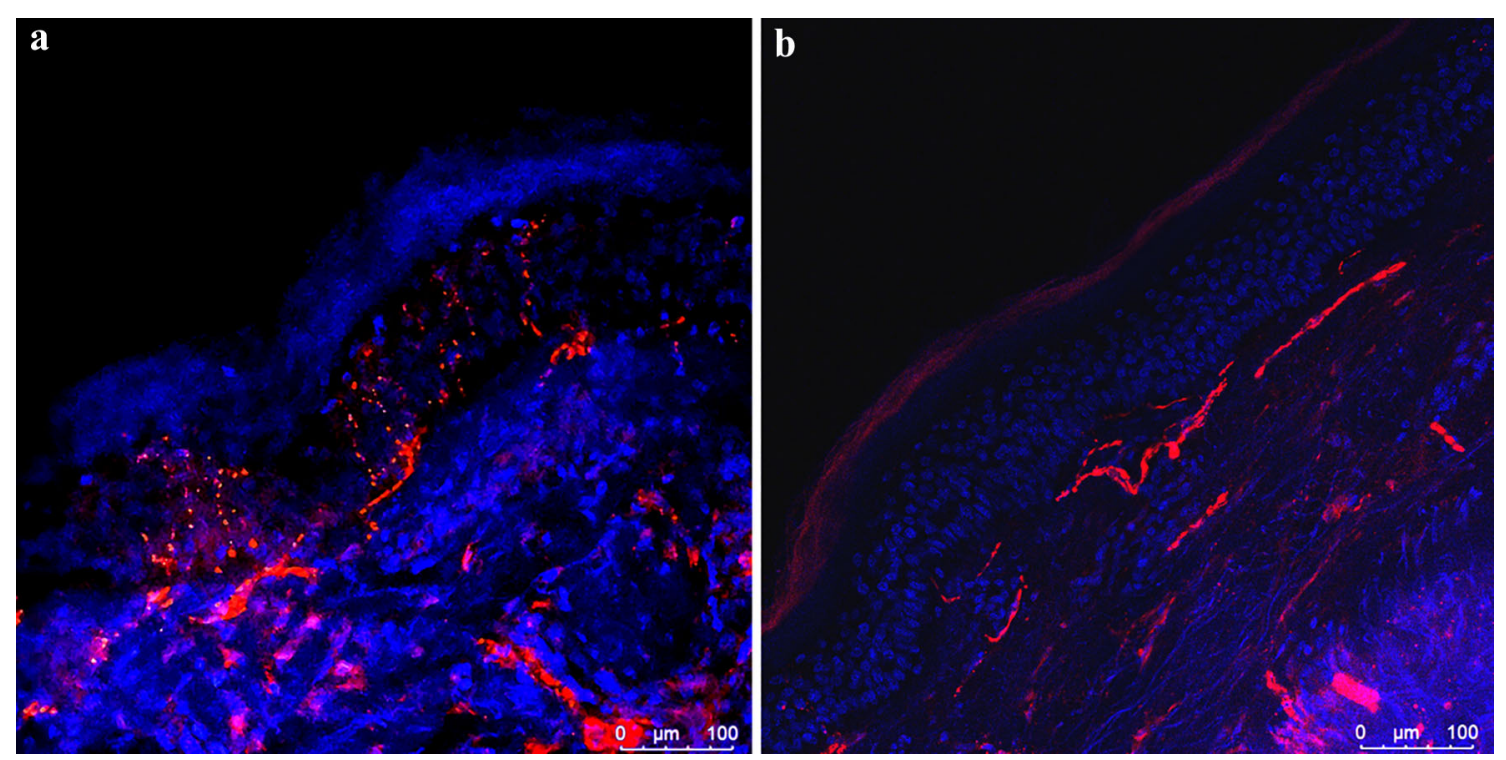

Fig. 2 PGP9.5 Immunofluorescence in human skin biopsy (a: Healthy subject. b: Diabetic patient diagnosed with small fiber neuropathy. Blue area: DAPI staining indicating cell nucleus. Red lines: PGP9.5-labelled small nerve fiber) 
Table 1 Demographic and biochemical indexes of subjects undergoing skin biopsy

\begin{tabular}{|c|c|c|c|c|}
\hline $\begin{array}{l}\text { Demographic and } \\
\text { biochemical indexes }\end{array}$ & $\begin{array}{l}\text { Non-DPN group } \\
(n=7)\end{array}$ & $\begin{array}{l}\text { Pure SFN group } \\
(n=37)\end{array}$ & $\begin{array}{l}\text { Mixed DPN group } \\
(n=45)\end{array}$ & $P$ \\
\hline Age (years) & $55.7 \pm 14.6$ & $57.6 \pm 10.2$ & $57.4 \pm 11.4$ & 0.925 \\
\hline Male sex & $42.9 \%(n=3)$ & $59.5 \%(n=22)$ & $64.4 \%(n=29)$ & 0.543 \\
\hline $\operatorname{BMI}\left(\mathrm{kg} / \mathrm{m}^{2}\right)$ & $23.2 \pm 3.0$ & $24.1 \pm 3.2$ & $23.8 \pm 3.3$ & 0.775 \\
\hline $\mathrm{SBP}(\mathrm{mmHg})$ & $103.0 \pm 9.9$ & $121.7 \pm 13.5$ & $129.6 \pm 16.6$ & $0.027^{\mathrm{b}}$ \\
\hline $\mathrm{DBP}(\mathrm{mmHg})$ & $60.7 \pm 1.2$ & $71.9 \pm 9.9$ & $77.4 \pm 13.0$ & $0.025^{\mathrm{b}}$ \\
\hline RHR (bpm) & $64.7 \pm 2.9$ & $70.4 \pm 9.6$ & $75.4 \pm 10.6$ & $0.039^{\mathrm{b}}$ \\
\hline Duration (years) & $6.5(3.0,15.5)$ & $10.0(6.0,16.3)$ & $10.0(4.5,17.0)$ & 0.491 \\
\hline Family history of diabetes & $42.9 \%$ & $54.1 \%$ & $53.3 \%$ & 0.858 \\
\hline Smoking & $0 \%$ & $40.5 \%$ & $33.3 \%$ & 0.114 \\
\hline Alcohol intake & $0 \%$ & $16.2 \%$ & $22.2 \%$ & 0.339 \\
\hline HbAlc (\%) & $7.8(6.4,11.9)$ & $7.0(6.3,9.6)$ & $9.5(7.3,10.8)$ & $0.005^{\mathrm{c}}$ \\
\hline $\mathrm{FBG}(\mathrm{mmol} / \mathrm{L})$ & $7.9(6.0,9.6)$ & $6.6(5.5,8.6)$ & $7.8(5.8,9.8)$ & 0.220 \\
\hline $\mathrm{FCP}(\mathrm{pmol} / \mathrm{L})$ & $520.8(371.9,705.3)$ & $577.1(306.1,779.6)$ & $435.3(215.0,732.2)$ & 0.398 \\
\hline FINS $(\mu \mathrm{IU} / \mathrm{mL})$ & $6.7(5.3,8.9)$ & $7.1(3.7,11.1)$ & $6.2(2.9,9.4)$ & 0.733 \\
\hline PBG $(\mathrm{mmol} / \mathrm{L})$ & $15.3(11.7,17.6)$ & $12.4(9.8,14.9)$ & $15.6(11.1,18.5)$ & $0.041^{\mathrm{c}}$ \\
\hline PCP $(\mathrm{pmol} / \mathrm{L})$ & $2425.0(1310.0,3446.3)$ & $1374.0(860.8,2459.5)$ & $966.7(576.8,1352.0)$ & $0.001^{\mathrm{bc}}$ \\
\hline PINS $(\mu \mathrm{IU} / \mathrm{mL})$ & $36.8(13.2,51.8)$ & $32.5(9.6,50.0)$ & $13.4(7.3,26.4)$ & $0.019^{c}$ \\
\hline HOMA-IR & $2.5(1.6,3.4)$ & $2.3(0.9,3.3)$ & $2.1(1.2,4.0)$ & 0.853 \\
\hline \multicolumn{5}{|l|}{ Lipid profiles $(\mathrm{mmol} / \mathrm{L})$} \\
\hline TG & $0.87(0.6,1.2)$ & $1.2(0.8,1.7)$ & $1.2(0.9,1.9)$ & 0.155 \\
\hline $\mathrm{TC}$ & $3.2(2.3,4.6)$ & $4.2(3.5,4.8)$ & $4.3(3.7,5.1)$ & 0.197 \\
\hline HDL-C & $1.3(1.2,1.8)$ & $1.1(0.9,1.4)$ & $1.2(0.9,1.4)$ & 0.155 \\
\hline LDL-C & $1.5(0.7,2.5)$ & $2.3(2.0,2.9)$ & $2.4(2.0,3.2)$ & 0.159 \\
\hline $\mathrm{eGFR}\left(\mathrm{mL} / \mathrm{min} / 1.73 \mathrm{~m}^{2}\right)$ & $128.2 \pm 18.5$ & $121.3 \pm 28.0$ & $112.9 \pm 35.3$ & 0.345 \\
\hline $\mathrm{ACR}$ & $7.4(6.3,14.4)$ & $23.2(11.4,46.4)$ & $34.3(12.4,157.2)$ & $0.016^{\mathrm{b}}$ \\
\hline Folate $(\mathrm{ng} / \mathrm{mL})$ & $19.9(13.2,23.2)$ & $16.1(10.8,22.4)$ & $18.8(14.2,21.7)$ & 0.575 \\
\hline Vitamin B12 $(\mathrm{pg} / \mathrm{mL})$ & $599.9(440.3,632.3)$ & $513.0(409.6,822.1)$ & $694.8(442.6,1671.9)$ & 0.426 \\
\hline
\end{tabular}


Table 1 continued

\begin{tabular}{lllll}
\hline $\begin{array}{l}\text { Demographic and } \\
\text { biochemical indexes }\end{array}$ & $\begin{array}{l}\text { Non-DPN group } \\
(\boldsymbol{n}=7)\end{array}$ & $\begin{array}{l}\text { Pure SFN group } \\
(\boldsymbol{n}=\mathbf{3 7})\end{array}$ & $\begin{array}{l}\text { Mixed DPN group } \\
(\boldsymbol{n}=\mathbf{4 5})\end{array}$ & $\boldsymbol{P}$ \\
\hline $25-\mathrm{OHD}(\mathrm{ng} / \mathrm{mL})$ & $29.7(25.2,33.9)$ & $19.4(15.4,26.1)$ & $19.0(10.2,24.1)$ & $0.014^{\mathrm{b}}$ \\
\hline
\end{tabular}

Values in table are presented as the mean \pm standard deviation (SD) or the mean with the range (minimum-maximum) in parentheses, unless indicated otherwise

$D P N$ Diabetic polyneuropathy, $S F N$ small fiber neuropathy, $B M I$ body mass index, $S B P$ systolic blood pressure, $D B P$ diastolic blood pressure, $R H R$ resting heart rate, $H b A 1 c$ hemoglobin Alc, $F B G$ fasting blood glucose, $F C P$ fasting C-peptide, FINS fasting insulin, PBG 2-h postprandial blood glucose, PCP 2-h postprandial C-peptide, PINS 2-h postprandial insulin, HOMA-IR homeostasis model assessment of insulin resistance, $T G$ total triglyceride, $T C$ total cholesterol, $H D L-C$ high-density lipoprotein cholesterol, $L D L-C$ low-density lipoprotein cholesterol, $e G F R$ estimated glomerular filtration rate, $A C R$ Urinary albumin-creatinin ration, 25-OHD 25-hydroxyvitamin $\mathrm{D}$

${ }^{a}$ Pure SFN group vs. non-DPN group, $P \leq 0.05$

b Mixed DPN group vs. non-DPN group, $P \leq 0.05$

${ }^{c}$ Pure SFN group vs. mixed DPN group, $P \leq 0.05$

difference between the pure SFN group and the mixed DPN group. Motor nerve conduction velocity $(\mathrm{MCV})$ was the lowest in the mixed DPN group, while the NSS, NPRS, and average HESC/FESC in SUDOSCAN did not show significant differences among the three groups.

The mixed DPN group obtained the highest score for the CARTs, indicating the worst CAN. Among the four items of the CARTs, postural BP change was lower and deep breathing maximum-minimum (min-max) values were higher in the pure SFN group than in the mixed DPN group ( $P=0.023$ and $P=0.040$, respectively). The percentage of CAN was significantly higher in the mixed DPN group than in the non-DPN group and the pure SFN group $(P=0.003)$.

\section{Correlation Between IENFD and Related Clinical Indexes}

To investigate factors that may have an impact on IENFD, we used Spearman correlations and partial correlations to analyze statistically significant clinical indexes and IENFD in the proximal and distal parts of the leg. The results showed that IENFD was negatively correlated with systolic BP and ACR in the distal leg $(r=-0.256, \quad P=0.045, \quad$ and $\quad r=-0.247$, $P=0.024$, respectively). However, following adjustment for age and duration, a correlation did not exist $(r=-0.298, P=0.077$, and $r=-0.153, \quad P=0.373, \quad$ respectively). CART scores were negatively correlated with IENFD in the distal leg in the raw correlation $(r=-0.385$, $P=0.002)$, and following adjustment for age or age and duration, there was still a negative correlation between the two indexes $(r=-0.473, \quad P=0.003, \quad$ and $\quad r=-0.513$, $P=0.001$, respectively) (Table 3 ).

\section{Follow-up of Pure SFN and Mixed DPN Subjects}

To understand the outcome of patients with pure SFN and mixed DPN, we conducted a follow-up of collected baseline values, with the follow-up period ending on 28 October, 2020. The follow-up analysis included 17 patients with pure SFN, with an average age of $55.0 \pm 7.5$ years, average duration of diabetes of $9.0 \pm 5.7$ years, average BMI of $25.0 \pm 2.9 \mathrm{~kg} /$ $\mathrm{m}^{2}$, and a median follow-up of 15 (max-min 12, 20) months, and nine patients with mixed DPN, with an average age of $62.9 \pm 11.1$ years, average duration of diabetes of $15.3 \pm 9.5$ years, average BMI of $24.4 \pm 3.1 \mathrm{~kg} / \mathrm{m}^{2}$, and a median follow-up of 12 (max-min 8.5, 16.5) months. Biochemical and neurological indexes were assessed during the follow-up.

For both groups, no changes were seen in the glucose and lipid profiles, ACR, and eGFR at the final visit. Among micronutrients, only vitamin B12 was increased at the final visit in the pure SFN group $(P=0.028)$. Regarding neurological 
Table 2 Neurological indexes of subjects undergoing skin biopsy

\begin{tabular}{lllll}
\hline Neurological indexes & $\begin{array}{l}\text { Non-DPN group } \\
(\boldsymbol{n}=7)\end{array}$ & $\begin{array}{l}\text { Pure SFN group } \\
(\boldsymbol{n}=\mathbf{3})\end{array}$ & $\begin{array}{l}\text { Mixed DPN group } \\
(\boldsymbol{n}=45)\end{array}$ & $\boldsymbol{P}$ \\
\hline IENFD of the proximal leg $(/ \mathrm{mm})$ & $11.1(8.9,11.4)$ & $2.3(1.0,4.9)$ & $3.0(1.2,4.0)$ & $0.004^{\mathrm{a}, \mathrm{b}}$ \\
IENFD of the distal leg $(/ \mathrm{mm})$ & $15.8(14.0,18.0)$ & $7.0(3.4,9.9)$ & $4.5(3.0,7.0)$ & $0.000^{\mathrm{a}, \mathrm{b}}$ \\
NSS & $4.0(3.8,7.5)$ & $5.0(4.0,7.0)$ & $7.0(4.3,9.0)$ & 0.119 \\
NPRS & $0.5(0,2.3)$ & $0(0,3.0)$ & $1.0(0,5.8)$ & 0.533 \\
CAN & $28.6 \%$ & $33.3 \%$ & $75 \%$ & $0.003^{\mathrm{b}, \mathrm{c}}$ \\
CART score & $1.0(1.0,2.5)$ & $1.5(1.1,2.0)$ & $2.5(1.0,3.0)$ & $0.023^{\mathrm{c}}$ \\
Postural BP change $(\mathrm{mmHg})$ & $7.5(-7.0,10.5)$ & $3.0(-6.0,13.0)$ & $12(4,21)$ & $0.023^{\mathrm{c}}$ \\
Deep breathing $(\mathrm{bpm})$ & $11.7(6.9,13.5)$ & $8.8(4.7,15.2)$ & $5.9(4.0,8.5)$ & $0.040^{\mathrm{b}, \mathrm{c}}$ \\
Valsalva ratio & $1.13(1.06,1.19)$ & $1.16(1.13,1.29)$ & $1.12(1.08,1.23)$ & 0.076 \\
30:15 ratio & $1.02(1.00,1.07)$ & $1.05(0.96,1.07)$ & $1.00(1.00,1.05)$ & 0.582 \\
Average HESC in hands $(\mu S)$ & $76.0(70.9,86.4)$ & $64.5(46.5,74.0)$ & $58.5(44.5,69.5)$ & 0.056 \\
Average FESC $(\mu S)$ & $85.8(74.4,90.4)$ & $72.0(65.0,80.5)$ & $70.5(45.0,80.0)$ & 0.056 \\
MCV of common peroneal nerve $(\mathrm{ms})$ & $44.1 \pm 4.4$ & $43.7 \pm 4.1$ & $38.3 \pm 5.1$ & $0.000^{\mathrm{b}, \mathrm{c}}$ \\
MCV of tibial nerve $(\mathrm{ms})$ & $42.7 \pm 3.4$ & $43.9 \pm 4.4$ & $38.8 \pm 4.9$ & $0.000^{\mathrm{c}}$ \\
\hline
\end{tabular}

Values in table are presented as the mean $\pm \mathrm{SD}$ or the mean with the range (minimum-maximum) in parentheses, unless indicated otherwise

IENFD Intra-epidermal nerve fiber density, NSS Neuropathy Symptom Score, NPRS numerical pain rating scale, CAN cardiovascular autonomic neuropathy, CART cardiovascular autonomic reflex tests, HESC electrochemical skin conductance in hands, FESC electrochemical skin conductance in feet, $M C V$ motor conduction velocity

${ }^{a}$ Pure SFN group vs. non-DPN group, $P \leq 0.05$

${ }^{b}$ Mixed DPN group vs. non-DPN group, $P \leq 0.05$

${ }^{c}$ Pure SFN group vs. mixed DPN group, $P \leq 0.05$

indexes, the NSS, NPRS, CARTs, SUDOSCAN, and NCV tests were conducted during the follow-up. The MCVs of the common peroneal nerve $(P=0.025)$ and tibial nerve $(P=0.047)$ were decreased in the mixed DPN group. However, the MCV of the common peroneal nerve showed an upward trend in the pure SFN group $(P=0.045)$ (Table 4$)$.

\section{DISCUSSION}

We report here an overall evaluation of the metabolic indexes in Chinese patients with T2DM with SFN based on skin biopsy results. In addition, neurological tests, including those on cardiovascular autonomic function, were performed on these subjects and the results assessed.

IENFD is an important parameter for evaluating the severity of SFN by calculating the number of skin nerves per unit length [10]. However, its reference range varies based on race, region, and staining method used [11]. In our study, we first established the reference range of IENFD in our region by enrolling healthy subjects who then underwent skin biopsy. The lower 5 th percentile of IENFD at the proximal thigh and the distal thigh was 10.0/ $\mathrm{mm}$ and $8.1 / \mathrm{mm}$, respectively. In their study, Kennedy et al. $[12,13]$ reported that the lower 5th percentile of IENFD at the distal leg was 


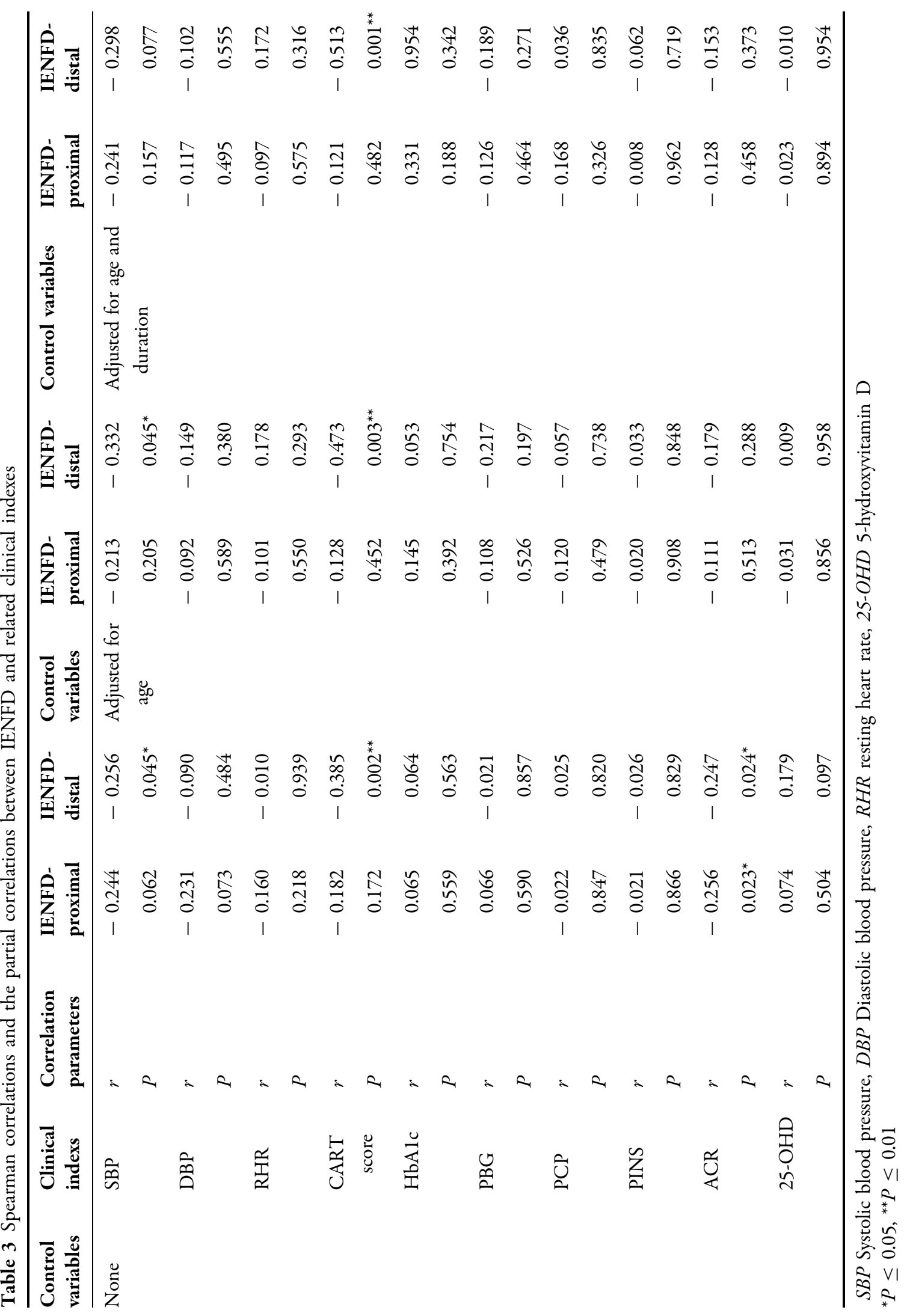


Table 4 Biochemical and neurological indexes of patients with pure SFN and mixed DPN during the follow-up

\begin{tabular}{|c|c|c|c|c|c|c|}
\hline \multirow{2}{*}{$\begin{array}{l}\text { Biochemical and } \\
\text { neurological indexes }\end{array}$} & \multicolumn{2}{|c|}{ Pure SFN group $(n=17)$} & \multicolumn{2}{|c|}{ Mixed DPN group $(n=9)$} & \multirow[t]{2}{*}{$P 1$} & \multirow[t]{2}{*}{$P 2$} \\
\hline & At initial visit & At final visit & At initial visit & At final visit & & \\
\hline HbAlc (\%) & $6.7(6.1,8.5)$ & $6.8(6.2,7.5)$ & $10.2(8.3,10.5)$ & $7.9(6.8,10.5)$ & 0.600 & 0.236 \\
\hline $\mathrm{FBG}(\mathrm{mmol} / \mathrm{L})$ & $7.1(5.5,8.2)$ & $6.4(5.3,7.5)$ & $7.0(5.8,8.4)$ & $6.4(5.5,9.4)$ & 0.552 & 0.953 \\
\hline $\mathrm{FCP}(\mathrm{pmol} / \mathrm{L})$ & $\begin{array}{l}731.2(460.0 \\
851.2)\end{array}$ & $\begin{array}{l}528.0(421.5 \\
688.0)\end{array}$ & $\begin{array}{l}277.7(143.8, \\
638.4)\end{array}$ & $\begin{array}{l}407.0(209.6 \\
527.6)\end{array}$ & 0.433 & 0.091 \\
\hline FINS $(\mu \mathrm{IU} / \mathrm{mL})$ & $8.5(4.4,12.4)$ & $6.0(3.1,9.9)$ & $6.9(2.2,21.2)$ & $10.2(2.7,32.5)$ & 0.182 & 0.310 \\
\hline PBG (mmol/L) & $12.4(9.6,13.7)$ & $11.0(9.0,15.1)$ & $13.7(7.7,17.7)$ & $\begin{array}{c}11.8(10.8 \\
15.1)\end{array}$ & 0.224 & 0.866 \\
\hline $\mathrm{PCP}(\mathrm{pmol} / \mathrm{L})$ & $\begin{array}{l}1540.0(1331.3 \\
2766.0)\end{array}$ & $\begin{array}{c}1798.0(1483.5 \\
2272.0)\end{array}$ & $\begin{array}{c}966.7(482.9, \\
1430.5)\end{array}$ & $\begin{array}{c}917.8(524.6 \\
1510.5)\end{array}$ & 0.203 & 0.594 \\
\hline PINS $(\mu \mathrm{IU} / \mathrm{mL})$ & $32.5(13.9,42.9)$ & $36.8(21.1,57.8)$ & $20.8(7.9,25.0)$ & $15.9(9.6,65.4)$ & 0.071 & 0.735 \\
\hline HOMA-IR & $2.2(0.9,3.5)$ & $1.5(0.7,2.9)$ & $2.1(0.8,4.7)$ & $3.2(1.2,9.3)$ & 0.328 & 0.237 \\
\hline \multicolumn{7}{|l|}{ Lipid profiles $(\mathrm{mmol} / \mathrm{L})$} \\
\hline TG & $1.2(0.7,1.6)$ & $1.3(0.7,1.8)$ & $1.3(0.8,1.6)$ & $1.1(0.6,1.7)$ & 0.975 & 0.314 \\
\hline TC & $4.5(4.0,4.9)$ & $4.3(3.6,4.9)$ & $4.3(3.6,4.4)$ & $3.8(3.3,4.4)$ & 0.133 & 0.515 \\
\hline HDL-C & $1.2(0.9,1.5)$ & $1.3(0.9,1.5)$ & $1.4(1.0,1.6)$ & $1.2(1.1,1.5)$ & 1.00 & 0.635 \\
\hline LDL-C & $2.6(2.2,2.8)$ & $2.3(1.9,2.9)$ & $2.4(1.8,2.7)$ & $2.2(1.6,2.5)$ & 0.363 & 0.374 \\
\hline $\mathrm{eGFR}\left(\mathrm{mL} / \mathrm{min} / 1.73 \mathrm{~m}^{2}\right)$ & $128.0 \pm 20.0$ & $131.8 \pm 23.7$ & $106.6 \pm 27.1$ & $108.5 \pm 64.3$ & 0.599 & 0.917 \\
\hline ACR & $27.7(14.9,57.5)$ & $21.9(4.7,39.2)$ & $\begin{array}{c}34.0(11.6 \\
103.6)\end{array}$ & $\begin{array}{c}26.1(11.1, \\
238.1)\end{array}$ & 0.972 & 0.091 \\
\hline Folate $(\mathrm{ng} / \mathrm{mL})$ & $12.4(9.9,19.8)$ & $12.5(8.5,17.5)$ & $\begin{array}{c}19.1(15.1 \\
22.8)\end{array}$ & $12.6(9.2,18.6)$ & 0.237 & 0.285 \\
\hline Vitamin B12 (pg/mL) & $\begin{array}{l}438.9(391.0, \\
736.0)\end{array}$ & $\begin{array}{c}599.0(524.8 \\
1502.3)\end{array}$ & $\begin{array}{c}771.0(524.6 \\
2000.0)\end{array}$ & $\begin{array}{l}497.0(428.5 \\
636.9)\end{array}$ & $0.028^{*}$ & 0.068 \\
\hline 25-OHD (ng/mL) & $19.1(14.9,26.9)$ & $29.1(24.2,32.9)$ & $17.9(9.7,21.9)$ & $\begin{array}{c}13.3(12.8 \\
24.7)\end{array}$ & 0.131 & 0.674 \\
\hline NSS & $5.0(4.0,7.0)$ & $4.0(2.0,5.0)$ & $7.5(4.5,9.0)$ & $8.0(6.0,9.0)$ & 0.713 & 0.593 \\
\hline NPRS & $1.5(0,4.5)$ & $1.0(0,4.0)$ & $2.0(0,6.5)$ & $5.0(3.0,6.0)$ & 0.583 & 0.414 \\
\hline CART score & $1.5(1.0,2.0)$ & $2.0(0.5,3.0)$ & $2.8(2.1,3.6)$ & $2.0(2.0,2.8)$ & 0.892 & 0.461 \\
\hline Average HESC $(\mu S)$ & $57.8(48.8,74.5)$ & $57.3(48.0,65.5)$ & $\begin{array}{c}48.0(15.5 \\
71.3)\end{array}$ & $\begin{array}{c}56.5(22.5 \\
65.5)\end{array}$ & 0.515 & 1.000 \\
\hline Average FESC $(\mu S)$ & $71.8(64.0,77.3)$ & $65.8(54.5,70.4)$ & $\begin{array}{l}54.0(16.1 \\
79.0)\end{array}$ & $\begin{array}{c}63.0(13.5 \\
70.5)\end{array}$ & 0.260 & 0.176 \\
\hline
\end{tabular}


Table 4 continued

\begin{tabular}{|c|c|c|c|c|c|c|}
\hline \multirow{2}{*}{$\begin{array}{l}\text { Biochemical and } \\
\text { neurological indexes }\end{array}$} & \multicolumn{2}{|c|}{ Pure SFN group $(n=17)$} & \multicolumn{2}{|c|}{ Mixed DPN group $(n=9)$} & \multirow[t]{2}{*}{$P 1$} & \multirow[t]{2}{*}{$P 2$} \\
\hline & At initial visit & At final visit & At initial visit & At final visit & & \\
\hline $\begin{array}{l}\text { MCV of common peroneal } \\
\text { nerve (ms) }\end{array}$ & $43.1 \pm 4.7$ & $46.0 \pm 2.4$ & $41.0 \pm 2.2$ & $35.4 \pm 1.4$ & $0.045^{*}$ & $0.025^{*}$ \\
\hline MCV of tibial nerve (ms) & $43.4 \pm 6.0$ & $46.9 \pm 4.0$ & $36.6 \pm 3.1$ & $34.2 \pm 1.4$ & 0.093 & $0.047^{*}$ \\
\hline
\end{tabular}

Values in table are presented as the mean \pm SD or the mean with the range (minimum-maximum) in parentheses, unless indicated otherwise

P1 Pure SFN group at the initial visit vs. pure SFN group at the final visit, $P 2$ mixed SFN group at the initial visit vs. SFN group at the final visit

${ }^{*} P \leq 0.05$

20.0/mm in subjects aged $20-59$ years and $11.8 /$ $\mathrm{mm}$ in subjects aged $>60$ years. However, conversely, McArthur et al. [14] found no sex or age effect in the IENFD of healthy subjects. As we found no significant difference in IENFD between subjects aged 20-50 years and those aged 51-80 years, we used a unified cutoff value to diagnose SFN.

Although the IENFD in the pure SFN group was significantly lower than that in the nonDPN group, there was no significant difference in the IENFD between the group with pure SFN and that with mixed DPN. This result indicates that SFN may have a unique pathophysiology rather than simply being an "early stage" of polyneuropathy.

Patients in the pure SFN group manifested better islet function, including lower $\mathrm{HbA}_{1 \mathrm{c}}$ and postprandial blood glucose, accompanied by higher postprandial insulin and C-peptide levels, compared to patients in the mixed DPN group. However, the eGFR and ACR did not differ between the two groups, indicating that a longer follow-up period was needed to assess diabetic microangiopathy.

We noted that the level of vitamin $\mathrm{D}$ was lower in the mixed DPN group than in the nonDPN group, which is in line with results from several previous studies [15-17]. Possible mechanisms include a role of vitamin $\mathrm{D}$ in protecting Schwann cells against advanced glycation end product (AGE)-induced apoptosis [18] and the promotion of proangiogenic molecules [19]. Further studies are needed to focus on vitamin $\mathrm{D}$ in the protection against diabetic neuropathy and the related molecular mechanisms.

Several studies have paid more attention to diabetic cardiovascular autonomic neuropathy (DCAN) in recent years. As an important type of autonomic neuropathy, DCAN can increase mortality associated with cardiovascular diseases [20-22]. However, it usually has an insidious onset and is easily neglected by clinicians. CARTs are the gold standard for screening for DCAN [23]. HRV, including deep breathing, the Valsalva maneuver, and lying-to-standing test, are used to test parasympathetic function. Orthostatic hypotension indicates impairment in sympathetic function [24].

In this study, the item of deep breathing max-min, a marker of the excitability of the parasympathetic nervous system, was lower in patients with pure SFN than in the non-DPN group, although there was no between-group difference in total CART score. Additionally, partial correlation analysis showed a negative correlation between IENFD of the distal leg and CART scores even after adjusting for age and duration of diabetes. In general, CARTs are vital to early screening for DCAN in diabetic patients in terms of managing long-term severe complications.

After the baseline study of SFN confirmed by skin biopsy, we conducted a follow-up of patients with pure SFN and mixed DPN. No changes were seen in islet function or lipid and kidney profiles between the two groups. 
Vitamin B12 and MCV of the common peroneal nerve were increased at the final visit in the pure SFN group. Conversely, the MCVs of the common peroneal nerve and tibial nerve were decreased in the mixed DPN group.

In a previous study, MacDonald et al. [25] reported a retrospective analysis of 101 patients with biopsy-confirmed SFN, and the average follow-up was 6.2 years. These authors found that SFN tended to be stable and rarely affected ambulation and employment status. However, electrophysiological tests were not assessed in that study, and the etiology of SFN was diverse, including hyperglycemia, immune dysfunction, vitamin B12 deficiency, among others. Løseth et al. [26] evaluated the progression of 35 neuropathy patients with type 1 or type $2 \mathrm{DM}$ and noted that there was minimal progression of large fiber neuropathy in both groups.

In our study, the MCV of the common peroneal nerve increased in the pure SFN group. The reason for this improvement in large fiber neuropathy in patients with pure SFN remains unknown, but may be partly due to the individual pathophysiological mechanism of SFN. Although HbA1c and fasting C-peptide levels improved in the mixed DPN group, the MCV of the lower limbs had deteriorated by the final visit. This phenomenon is also consistent with results from previous studies related to intensive blood glucose control and neurological complications, indicating that tighter blood glucose control did not lead to less severe neuropathy [27-29]. Therefore, more attention should be paid to the early recognition of SFN in diabetic patients with a high risk of large fiber neuropathy.

Regarding vitamin B12, the differences between the two groups may be attributed to the usage of nutritional supplements by some patients. Additionally, we noted that age at the initial visit was higher in the mixed DPN group, which meant that the large fiber nerve was probably vulnerable due to age-related factors. Thus, a longer follow-up time is needed in further studies related to SFN.

The study has several limitations that should be addressed. First, the number of healthy subjects was relatively small, and due to heterogeneity in IENFD, the diagnosis of SFN could only be defined by the reference range determined from the local region. Second, the subjects were recruited from the inpatient department, which may not represent the overall population of patients with SFN. Third, this was a single-center study of Chinese patients with T2DM, and prospective multicenter clinical trials are needed in the future. Last, the follow-up was relatively short to evaluate the features of patients with pure SFN and mixed DPN.

\section{CONCLUSIONS}

In summary, we thoroughly investigated the clinical characteristics of Chinese diabetic patients with SFN based on skin biopsy; to our knowledge this is the first such study. Better islet function and cardiovascular autonomic function were observed in those with pure SFN compared with patients with mixed DPN. CART scores were negatively correlated with IENFD in the distal leg even after adjusting for age and duration of diabetes. The metabolic and neurological indexes appeared to be relatively stable in the follow-up of subjects with pure SFN. Additionally, it is necessary to attach importance to the early screening of CAN in diabetic patients.

\section{ACKNOWLEDGEMENTS}

Special thanks to Hongyu Huang, Quan Zhang, and Lu Zhou for photographing stained slices, and to Dr. Lan Wang for the theoretical guidance in neurology. Donghui Yang participated in patient-related instrumental examinations. The authors would especially like to thank all volunteers for their participation in this study.

Funding. This work was supported by the National Natural Science Foundation of China Grant Awards [81570737, 81570736] and the Key Research and Development Program of Jiangsu Province of China [BE2015604]. The journal's rapid service fee was funded by the sponsors. 
Authorship. All named authors meet the International Committee of Medical Journal Editors (ICMJE) criteria for authorship for this article, take responsibility for the integrity of the work as a whole, and have given their approval for this version to be published.

Authors' Contributions. D.Z and Y.B. conceived and designed the study. C.L., W.N, C.C., and J.J. conducted the skin biopsy. C.L. performed all data analysis and drafted the manuscript. W.C. performed the NCV test and W.W. contributed to the revision of the manuscript. All the other authors critically reviewed and approved the final manuscript.

Data Availability. All data generated or analyzed during this study are included in this published article/as supplementary information files.

Disclosures. Chenxi Li, Weimin Wang, Wenyu Ni, Yu Jin, Simin Guo, Jiewen Jin, Chuhui Chen, Wei Chen, Yan Bi and Dalong Zhu declare that they have nothing to disclose.

Compliance with Ethics Guidelines. All recruited participants gave their written informed consent before enrolment. The study (NCT04071535) was registered at ClinicalTrials.gov and was approved by the Ethics Committee of Drum Tower Hospital Affiliated to Nanjing University Medical School (No. 2017-159-03) and was compliant with the declaration of Helsinki 1964 and its later amendments.

Open Access. This article is licensed under a Creative Commons Attribution-NonCommercial 4.0 International License, which permits any non-commercial use, sharing, adaptation, distribution and reproduction in any medium or format, as long as you give appropriate credit to the original author(s) and the source, provide a link to the Creative Commons licence, and indicate if changes were made. The images or other third party material in this article are included in the article's Creative Commons licence, unless indicated otherwise in a credit line to the material. If material is not included in the article's Creative Commons licence and your intended use is not permitted by statutory regulation or exceeds the permitted use, you will need to obtain permission directly from the copyright holder. To view a copy of this licence, visit http://creativecommons.org/licenses/by$\mathrm{nc} / 4.0 /$.

\section{REFERENCES}

1. Li Y, Teng D, Shi X, et al. Prevalence of diabetes recorded in mainland China using 2018 diagnostic criteria from the American Diabetes Association: national cross sectional study. BMJ. 2020;369: m997. https://doi.org/10.1136/bmj.m997.

2. Callaghan BC, Cheng HT, Stables CL, Smith AL, Feldman EL. Diabetic neuropathy: clinical manifestations and current treatments. Lancet Neurol. 2012;11:521-34. https://doi.org/10.1016/S14744422(12)70065-0.

3. Themistocleous AC, Ramirez JD, Serra J, Bennett DLH. The clinical approach to small fibre neuropathy and painful channelopathy. Pract Neurol. 2014. https://doi.org/10.1136/practneurol-2013000758

4. Alberti K, Zimmet P. Definition, diagnosis and classification of diabetes mellitus and its complications. Report of a WHO consultation. Part 1: Diagnosis and classification of diabetes mellitus. Diabet Med. 1998;15:539-53.

5. Young MJ, Boulton AJ, MacLeod AF, Williams DR, Sonksen PH. A multicentre study of the prevalence of diabetic peripheral neuropathy in the United Kingdom hospital clinic population. Diabetologia. 1993;36:150-4. https://doi.org/10.1007/ bf00400697.

6. Farrar JT, Young JP Jr, LaMoreaux L, Werth JL, Poole RM. Clinical importance of changes in chronic pain intensity measured on an 11-point numerical pain rating scale. Pain. 2001;94:149-58. https://doi.org/ 10.1016/s0304-3959(01)00349-9.

7. Tesfaye S, Boulton AJ, Dyck PJ, et al. Diabetic neuropathies: update on definitions, diagnostic criteria, estimation of severity, and treatments. J Diabetes Care. 2010;33:2285-93. https://doi.org/10.2337/ dc10-1303.

8. Casellini CM, Parson HK, Richardson MS, Nevoret ML, Vinik AI. Sudoscan, a noninvasive tool for detecting diabetic small fiber neuropathy and autonomic dysfunction. Diabetes Technol Ther. 
2013;15:948-53. https://doi.org/10.1089/dia.2013. 0129.

9. Hsieh ST. EFNS guidelines on the use of skin biopsy in the diagnosis of peripheral neuropathy. Eur J Neurol. 2007;13: e9. https://doi.org/10.1111/j. 1468-1331.2005.01260.x.

10. Lauria G, Cornblath DR, Johansson O, et al. EFNS guidelines on the use of skin biopsy in the diagnosis of peripheral neuropathy. Eur J Neurol. 2005;12: 747-58. https://doi.org/10.1111/j.1468-1331.2005. 01260.x.

11. Shikuma CM, McArthur JC, Ebenezer GJ, et al. Ethnic differences in epidermal nerve fiber density. Muscle Nerve. 2013;48:462-4. https://doi.org/10. 1002/mus.23834.

12. Kennedy WR, Wendelschafer-Crabb G, Johnson T. Quantitation of epidermal nerves in diabetic neuropathy. Neurology. 1996;47:1042-8. https://doi. org/10.1212/wnl.47.4.1042.

13. Periquet MI, Novak V, Collins MP, et al. Painful sensory neuropathy: prospective evaluation using skin biopsy. Neurology. 1999;53:1641-7. https:// doi.org/10.1212/wnl.53.8.1641.

14. McArthur JC, Stocks EA, Hauer P, Cornblath DR, Griffin JW. Epidermal nerve fiber density: normative reference range and diagnostic efficiency. Arch Neurol. 1998;55:1513-20. https://doi.org/10.1001/ archneur.55.12.1513.

15. Almurdhi MM, Brown SJ, Bowling FL, et al. Altered walking strategy and increased unsteadiness in participants with impaired glucose tolerance and Type 2 diabetes relates to small-fibre neuropathy but not vitamin D deficiency. Diabet Med. 2017;34: 839-45. https://doi.org/10.1111/dme.13316.

16. Niu Y, Li J, Peng R, et al. Low vitamin D is associated with diabetes peripheral neuropathy in older but not in young and middle-aged patients. Diabetes Metab Res Rev. 2019;35: e3162. https://doi. org/10.1002/dmrr.3162.

17. Alam U, Petropoulos IN, Ponirakis G, et al. Vitamin $\mathrm{D}$ deficiency is associated with painful diabetic neuropathy. Diabetes Metab Res Rev. 2020. https:// doi.org/10.1002/dmrr.3361.

18. Xu S, Li J, Zhai M, et al. 1,25-(OH)(2)D(3) protects Schwann cells against advanced glycation end products-induced apoptosis through PKA-NF- $\kappa \mathrm{B}$ pathway. Life Sci. 2019;225:107-16. https://doi.org/ 10.1016/j.lfs.2019.03.068.

19. Trujillo V, Marín-Luevano P, González-Curiel I, et al. Calcitriol promotes proangiogenic molecules in keratinocytes in a diabetic foot ulcer model. J Steroid Biochem Mol Biol. 2017;174:303-11. https://doi.org/10.1016/j.jsbmb.2017.10.013.

20. Kuehl M, Stevens MJ. Cardiovascular autonomic neuropathies as complications of diabetes mellitus. Nat Rev Endocrinol. 2012;8:405-16. https://doi. org/10.1038/nrendo.2012.21.

21. Yun JS, Park YM, Cha SA, Ahn YB, Ko SH. Progression of cardiovascular autonomic neuropathy and cardiovascular disease in type 2 diabetes. Cardiovasc Diabetol. 2018;17:109. https://doi.org/10. 1186/s12933-018-0752-6.

22. Jun JE, Lee SE, Choi MS, et al. Clinical factors associated with the recovery of cardiovascular autonomic neuropathy in patients with type 2 diabetes mellitus. Cardiovasc Diabetol. 2019;18:29. https://doi.org/10.1186/s12933-019-0830-4.

23. Ewing DJ, Campbell IW, Clarke BF. Assessment of cardiovascular effects in diabetic autonomic neuropathy and prognostic implications. Ann Intern Med. 1980;92:308-11. https://doi.org/10.7326/ 0003-4819-92-2-308.

24. Spallone V, Ziegler D, Freeman R, et al. Cardiovascular autonomic neuropathy in diabetes: clinical impact, assessment, diagnosis, and management. Diabetes Metab Res Rev. 2011;27:639-53. https:// doi.org/10.1002/dmrr.1239.

25. MacDonald S, Sharma TL, Li J, Polston D, Li Y. Longitudinal follow-up of biopsy-proven small fiber neuropathy. Muscle Nerve. 2019;60:376-81. https://doi.org/10.1002/mus.26648.

26. Løseth S, Stålberg EV, Lindal S, et al. Small and large fiber neuropathy in those with type 1 and type 2 diabetes: a 5-year follow-up study. J Peripheral Nervous Syst. 2016;21:15-21. https://doi.org/10. 1111/jns.12154.

27. Group AC, Patel A, MacMahon S, et al. Intensive blood glucose control and vascular outcomes in patients with type 2 diabetes. $\mathrm{N}$ Engl J Med. 2008;358:2560-72. NEJMoa0802987. https://doi.org/10.1056/

28. Duckworth W, Abraira C, Moritz T, et al. Glucose control and vascular complications in veterans with type 2 diabetes. N Engl J Med. 2009;360:129-39. https://doi.org/10.1056/NEJMoa0808431.

29. Ismail-Beigi F, Craven T, Banerji MA, et al. Effect of intensive treatment of hyperglycaemia on microvascular outcomes in type 2 diabetes: an analysis of the ACCORD randomised trial. Lancet. 2010;376:419-30. https://doi.org/10.1016/S01406736(10)60576-4. 